International Journal of Agriculture, Environment and Bioresearch

Vol. 5, No. 05; 2020

ISSN: $2456-8643$

\title{
PROBLEM OF DRINKING WATER SUPPLY IN THE MUNICIPALITY OF BANIKOARA
}

\author{
YETONGNON Judith Eric Georges \\ Pierre Pagney Laboratory, Climate, Water, Ecosystems and Development (LACEEDE) ,University of Abomey \\ Calavi (UAC), Republic of Benin \\ https://doi.org/10.35410/IJAEB.2020.5566
}

\begin{abstract}
Most developing countries face enormous problems in accessing drinking water and managing water infrastructure. This study aims to analyze the problem of drinking water supply in the Municipality of Banikoara.

To achieve this, a methodological approach focused on data collection, processing and analysis of results was adopted. A set of methods such as observation, field survey, analysis of water samples, and statistical treatments which have obtained the different results.

From the analysis of the results, it emerges that modern wells, AEVs, FPMs are the main sources of access to drinking water in the Municipality. These structures serve the populations with a service rate of $35 \%$ which is below the rural rate which in fact $69 \%$. Insufficient water points force people to obtain supplies from various sources of safe water. Likewise, access to drinking water is confronted with other factors which are: the accessibility to drinking water, measured by the type of supply, the distance and the cost of the purchase, seems to make account of the different methods of access to drinking water. Faced with these problems, it is imperative to review the methods of water management in the Municipality.
\end{abstract}

Keywords: Problematic, Supply, drinking water, Municipality of Banikoara.

\section{INTRODUCTION}

Water is essential to all aspects of life and as such is the key to sustainable development (PNE, 2008). The availability of drinking water is therefore a fundamental condition for human life and one of the greatest challenges for the coming decades, especially in Africa (Christoph et al., 2009). According to WHO, 844 million people worldwide do not have basic access to safe drinking water (WHO, 2017). The water crisis we are going through is worrying. Today, $30 \%$ of the world's population still does not have access to drinking water at home (WHO, 2017). These present obvious challenges for the water supply. Similarly, some 2.1 billion people, or $30 \%$ of the world's population, still do not have access to domestic drinking water services and 4.5 billion, or $60 \%$, do not have access to services. safely managed sanitation facilities, according to a new joint report from the World Health Organization (WHO) and UNICEF.Access to drinking water in the world is one of the major challenges of our society. Indeed, food, health and all 
human activities depend on its availability in sufficient quantity and quality (Josling T., 2010). Groundwater exploitation, rainwater harvesting, construction public water networks are all projects on which the international community is committed. Providing access to drinking water throughout the world is an essential objective for populations (WHO, 1990).

Benin has significant water resources. Despite this potential, access to drinking water is a serious problem, both in terms of quantity and quality. Despite the stated ambitions of political and administrative authorities and development partners, the drinking water supply is far from being satisfied. The rate of drinking water supply in the localities of our country remains low with only about 48\% (RGPH 3). In the Municipality of Banikoara, access to drinking water remains a major challenge for a large part of the population. This research aims to study the problem of drinking water supply in the Municipality of Banikoara. It examines the difficulties of households in having access to drinking water. Thus, it will make decision-support tools available to public authorities.

\section{Presentation of the field of study}

Located in the North-West of Benin, the commune of Banikoara is one of the six communes of the department of Alibori. It lies between $11^{\circ} 18$ ' and $11^{\circ} 30^{\prime}$ ' north latitude and between $2^{\circ} 26$ 'and $2^{\circ} 43^{\prime}$ ' east longitude. It is limited to the North by the Municipality of Karimama, to the South by the Municipalities of Gogounou and Kérou, to the East by the Municipality of Kandi and to the West by Burkina Faso with an area of 4,383 km2 (Figure 1).

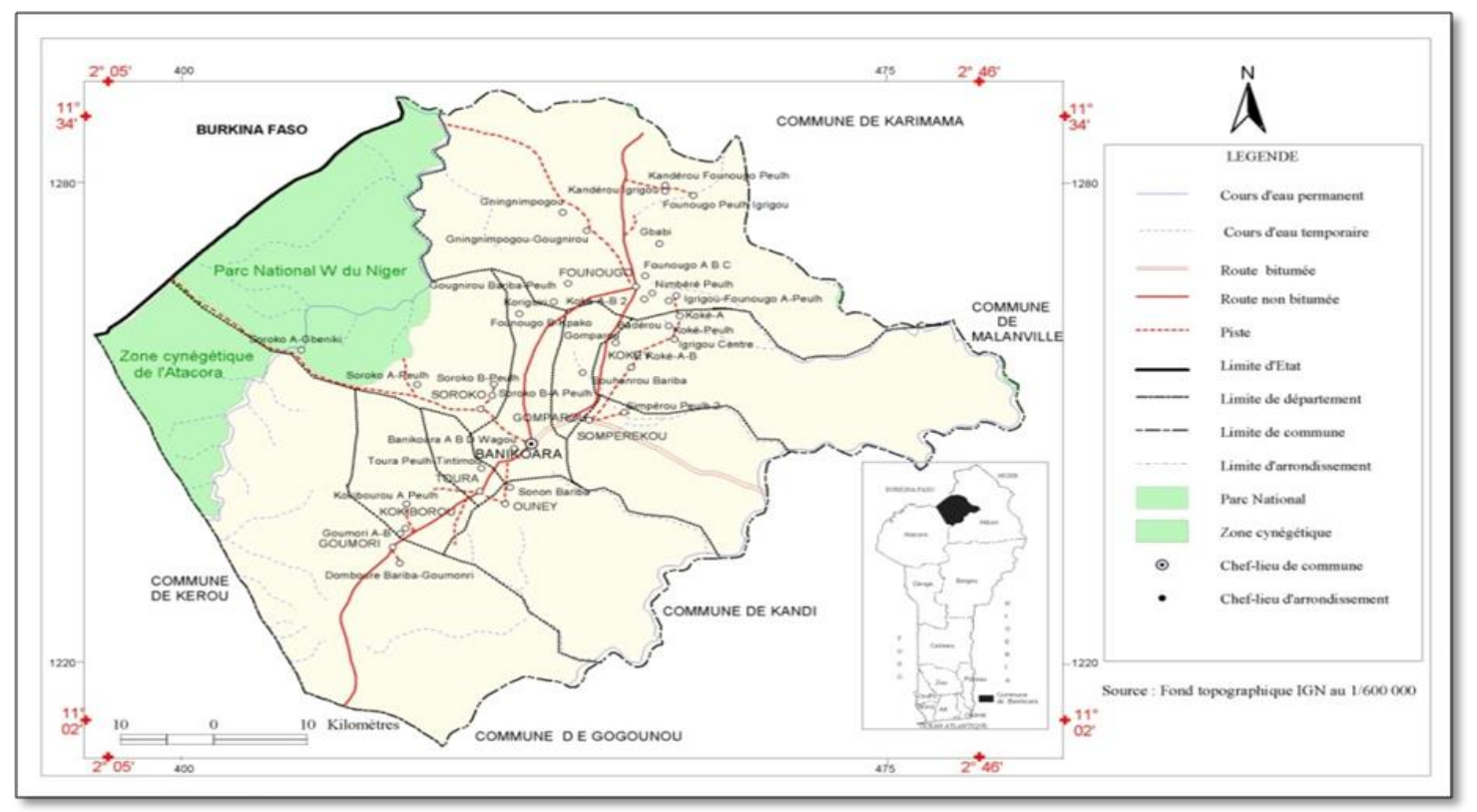

Figure 1: Situation of the Municipality of Banikoara

Banikoara Commune is influenced by a Sudanese-type climate (Adam and Boko, 1993). This is the area where the thermal amplitudes are strong, especially during the harmattan. Modeled in a 
slightly uneven relief with a terminal extension of the Atacora chain to the southwest and at an altitude varying between 200 and $300 \mathrm{~m}$, it presents a vast undulating peneplain (Adam and Boko, 1993). Its topography is also marked by spreading cuirasses, alternated with gently sloping glacis (Boko G. et al., 2009), which does not allow a great retention of water.

\section{DATA AND METHODS}

\subsection{Data}

To carry out this research, several data were used. These are rainfall data extracted from the ASECNA Benin database over the period 1960-2017, demographic data derived from the results of the general population and housing censuses of 1979, 1992, 2002 and the estimates of 2006, 2015 and 2025 obtained from INSAE and epidemiological data obtained from Banikoara Zone Hospital.

Surveys were carried out by means of questionnaires among the populations and local elected officials and in this vein a sample was determined. The sample is determined using the reasoned choice technique. The sample size is obtained from the formula of Schwartz (1995);

$$
\mathrm{X}=\mathrm{Z} \alpha^{2} \mathrm{xpq} / \mathrm{i}^{2}
$$

with: $X=$ the size of the sample; $Z \alpha=1.96$ reduced deviation corresponding to a risk $\alpha$ of $5 \% ; p$ $=\mathrm{n} / \mathrm{N}$; with $\mathrm{p}=$ proportion of households in the selected villages $(\mathrm{n})$ compared to the number of households in the ten (10) districts $(\mathrm{N}) ; \mathrm{q}=1-\mathrm{p}$ and $\mathrm{i}=5 \%$ margin of error.

A total of 202 households were surveyed in all ten districts of the municipality of Banikoara. There are also 23 resource people. The resource persons are made up of the village elders.

\subsection{Data processing method}

Several statistical protocols were used to characterize the problem of access to water in the Municipality of Banikoara. Among these;

The arithmetic mean is used to study rainfall regimes and other variables in the Commune. It is the fundamental parameter of central tendency. We used in "normal", the average calculated over a series of thirty-eight and thirty-two years. It is expressed as follows: $\bar{X}=\frac{1}{n} \sum_{i=1}^{n} x i$

The average made it possible to characterize the average rainfall state in the commune of Banikoara.

The calculation of the standard deviation makes it possible to evaluate the dispersion of the values around the "normal" mean. It is determined by calculating the square root of the variance:

$$
\sigma(x)=\sqrt{V}
$$

Where $\mathrm{V}$ is the variance 
The standard deviation is the quintessential indicator of variability.

From the calculation of the standard deviation, the study of the centralized reduced rainfall and hydrometric monthly and interannual anomalies was undertaken by standardizing the data. The anomalies on each station and on the different basins are calculated by the formula

$$
\dot{x}_{i}^{\prime}=\frac{x-\bar{X}}{a(x)}
$$

Next:

or:

$x_{i}^{\prime}=$ reduced centered anomaly for year i

$x i=$ the value of the variable,

$\bar{X}=$ the mean of the series.

$\sigma(x)=$ the standard deviation of the series

Expressed as a percentage, the coefficient of variation makes it possible to assess the degree of variability of rainfall and daily, monthly and annual hydrometry. This coefficient is the most satisfactory of the dispersion measurements in the comparative study of the variability of precipitation and the daily, seasonal and annual flows between the sub-basins. This is the ratio of

the standard deviation to the mean which is written as follows:

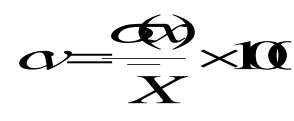

Or

$\bar{X}=$ the mean of the series.

$\sigma(x)=$ the standard deviation of the series

\section{RESULTS}

\subsection{Sources of supply in the Municipality of Banikoara}

The commune of Banikoara is supplied with drinking water by two main networks, the village water network and the National Water Company of Benin (SONEB).

\subsection{1 .SONEB network in the Municipality of Banikoara}

SONEB ensures the distribution of water in the capitals of the districts of Banikoara, Gomparou and Sompérékou. The SONEB network has only one storage tank reinforced in 2008 by the 
Yadikparou drilling. The current flow is $40 \mathrm{~m} 3$ with a capacity of $60 \mathrm{~m} 3$. It distributes water to 337 subscribers for 6,076 households in the three district capitals. Of the 337 subscribers, 267 are active 70 subscribers are inactive. The coverage rate of the SONEB network in the Municipality of Banikoara is estimated at $05.55 \%$. The neighborhoods that are most affected by the low coverage rate are: Yadikparou, Orougnonrou (aviation) and Démanou. In the districts which are served, SONEB water is consumed only during the dry season when the wells are dry.

\subsubsection{Village water supply in the Municipality of Banikoara}

The village water supply through its hydraulic equipment provides drinking water in the villages. The installation of this equipment is ensured by the DGEau at the request of the town halls. Depending on the size of the population and hydrogeological factors, we can have, AEV, FPM, modern wells, large diameter wells.

\subsubsection{Boreholes equipped with Motricity Pump (FPM)}

These are boreholes equipped with a submerged pump and a manual or foot-operated pumping system. The boreholes are four hundred and fifty-one (451) of which three hundred and ninetyeight (388) are functional. distributed in the ten districts of the Municipality of Banikoara and mainly supply the populations. Two models of boreholes equipped with Human Motricity Pumps (FPM) are installed. These are foot pumps and hand pumps (Photo 11 and 2).

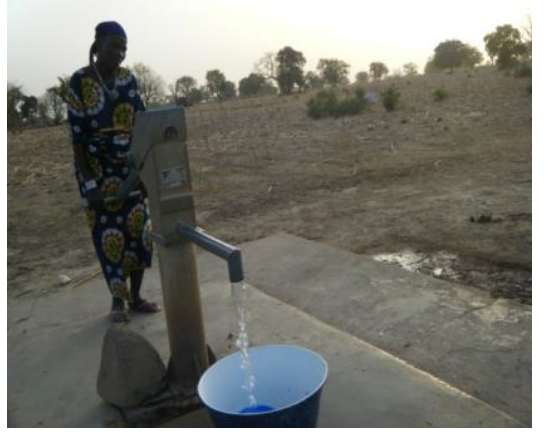

Photo 1: Borehole equipped with a manual pump in the Kokey district

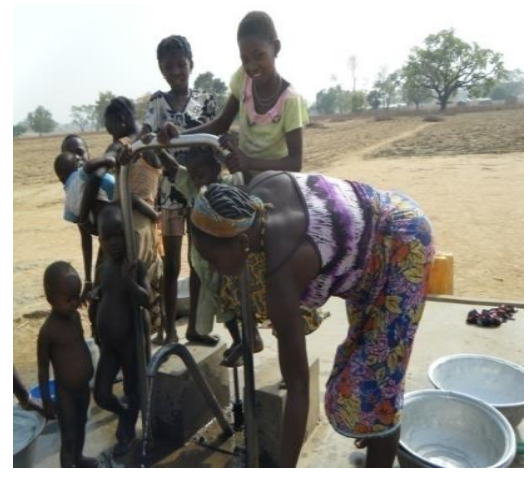

Photo 2: Borehole equipped with a foot pump in the district of Ounet 
Shooting: Yetongnon, 2019

\subsubsection{2 .Large diameter wells}

The large-diameter well system is generally carried out in regions where the water table is too deep (on the base for example) and where we want to reduce human effort to pump water and to have a greater flow (Koumassi, The large-diameter wells are fitted with a drawing system made up of a winch, a superstructure made of an anti-quagmire slab, a coping, a drainage channel and soak-off wells facilitate the hygienic maintenance of the premises (Photo 3). A total of 97 largediameter wells are being built in the ten districts of the Municipality.

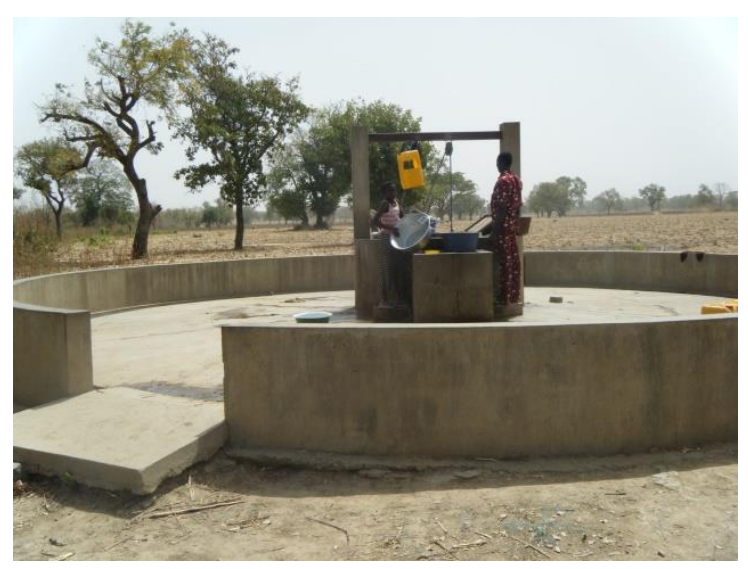

Photo 3: Drilling against well in the district of Gomparou

Shooting: Yetongnon, 2019

\subsubsection{3- Village Water Supply (AEV)}

EVA is often carried out by the State through DG-Eau and its partner structures.

The AEV generally consists of a borehole equipped with a motorized pumping system connected to a storage tank called a water tower (Photo 4) and to a water distribution network. AEVs are a good solution for supplying drinking water to large villages with a total population of more than 2000 inhabitants or for groups of villages and localities close to each other (DG-Eau, 2008). The water from the $\mathrm{AEV}$ is distributed through underground pipelines by means of standpipes (BF) and special connections (Photo 5). In total in the Municipality of Banikoara, three AEVs provide drinking water to the populations via 67 standpipes 


\section{International Journal of Agriculture, Environment and Bioresearch}

Vol. 5, No. 05; 2020

ISSN: $2456-8643$

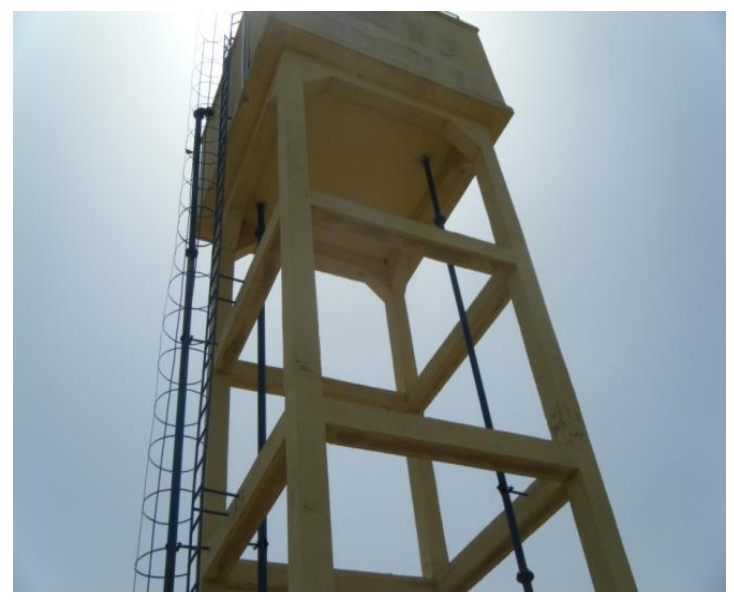

Photo 4: Water tower in the district of Goumori

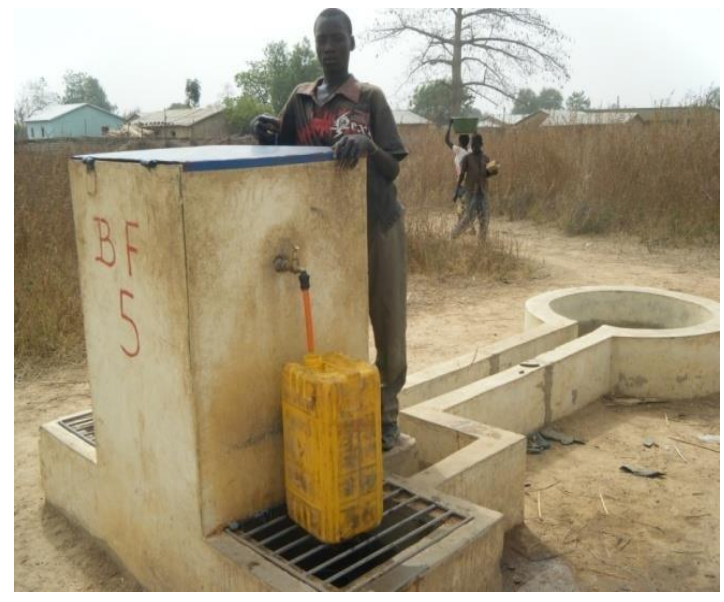

Photo 5: Fountain in the district of Toura

Shooting: Yetongnon, 2019

\subsection{Service rate in the Municipality of Banikoara}

The drinking water supply rate expresses the proportion of the population served with drinking water in relation to the total population.

According to the international standard for access to drinking water, a population of 250 inhabitants is required for a water point. Table 1 shows the drinking water supply rate in the Municipality of Banikoara.

Table 1: Water supply rate in the Municipality of Banikoara

\begin{tabular}{|l|l|l|l|l|}
\hline Boroughs & Population & $\begin{array}{l}\text { Total } \\
\text { EPE }\end{array}$ & $\begin{array}{l}\text { Population } \\
\text { desservie }\end{array}$ & $\begin{array}{l}\text { Service } \\
\text { rate }\end{array}$ \\
\hline Banikoara & 34803 & 34 & 34344 & 41,22 \\
\hline Founougo & 53616 & 87 & 16630 & 31,02 \\
\hline Gomparou & 26000 & 49 & 7190 & 27,65 \\
\hline Goumori & 37889 & 51 & 10711 & 28,27 \\
\hline Kokey & 21203 & 53 & 10637 & 50,26 \\
\hline Kokiborou & 12007 & 29 & 3912 & 32,56 \\
\hline Ounet & 23853 & 63 & 10936 & 45,85 \\
\hline
\end{tabular}




\begin{tabular}{|l|l|l|l|l|}
\hline Sompérékou & 28963 & 63 & 10936 & 37,76 \\
\hline Soroko & 10346 & 14 & 2948 & 28,49 \\
\hline Toura & 24412 & 41 & 8328 & 34,11 \\
\hline Total & $\mathbf{2 7 3 0 9 2}$ & $\mathbf{4 8 4}$ & $\mathbf{1 1 6 5 7 2}$ & $\mathbf{4 4 , 3 1}$ \\
\hline
\end{tabular}

Source: Fieldwork, 2019

From the analysis of the table, it emerges that the functional and perennial water points listed in the town of Banikoara serve a population estimated at 116,572 inhabitants out of a total of 273,092 inhabitants, which corresponds to a service rate of $44.31 \%$. The service rate varies from one borough to another. Thus, the districts of Founougo, Gomparou, Kokiborou, Goumori, Soroko, and Toura, have service rates lower than the municipal average with $31.02 \%, 27.65 \%$, $32.58 \%, 28,27 \%, 28.49 \%$ and $34.11 \%$ respectively. On the other hand, the districts of Kokey, Ounet, Banikoara center and Sompérékou respectively have drinking water service rates of $50.26 \%, 46.85 \%, 41.22 \%$ and $37.76 \%$. Only the Kokey district has a service rate slightly above $50 \%$. In any case, none has been able to reach the national standard of $67 \%$ in rural areas. Efforts therefore still need to be made in order to provide drinking water to the population. This low rate of access to drinking water forces populations to obtain supplies from unsanitary sources.

\subsection{Distribution of households by source of drinking water supply}

The people of Banikoara have several sources of drinking water supply. Figure 2 shows the distribution of households according to the sources of supply in the dry season in the commune of Banikoara.

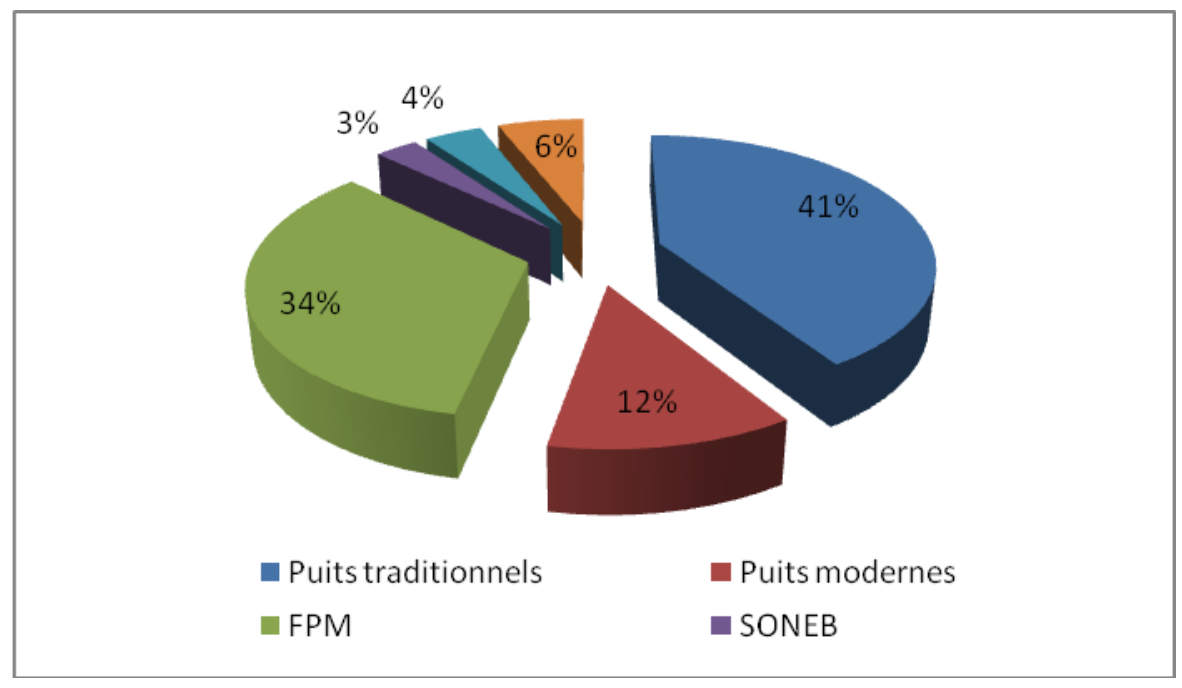

Figure 2: Distribution of households by source of supply 
Source: Survey results, 2019

The analysis of figure 2 reveals that of the 202 households surveyed in the commune of Banikoara, $41 \%$ use water from traditional wells, $33 \%$ use water from hand pumps, $12 \%$ use water from modern wells. , $6 \%$ use water from backwaters, $4 \%$ use water from standpipes and $3 \%$ use water from SONEB. The use of structures by the populations depends on the time of year. Hydraulic equipment is used more during the dry season when traditional wells run dry. But on the whole, the populations, given the insufficiency of hydraulic structures and financial difficulties, prefer to obtain supplies from rivers and traditional wells. Plate 1 presents some sources of supply in the Municipality of banikoara.

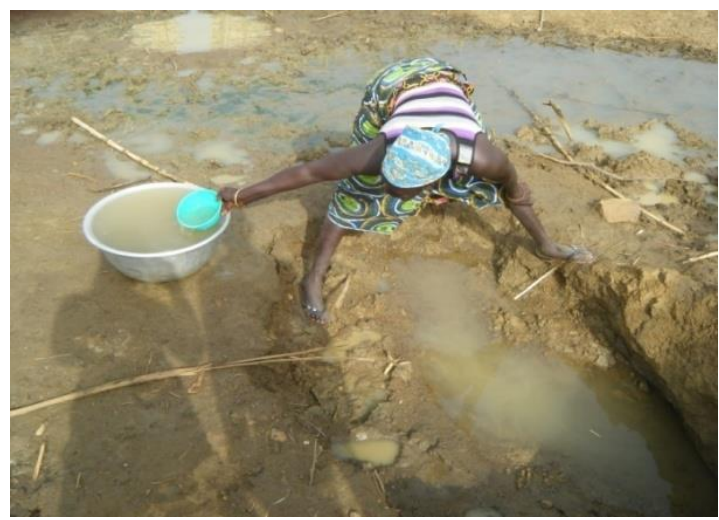

Photo 6: Water hole at Kokey

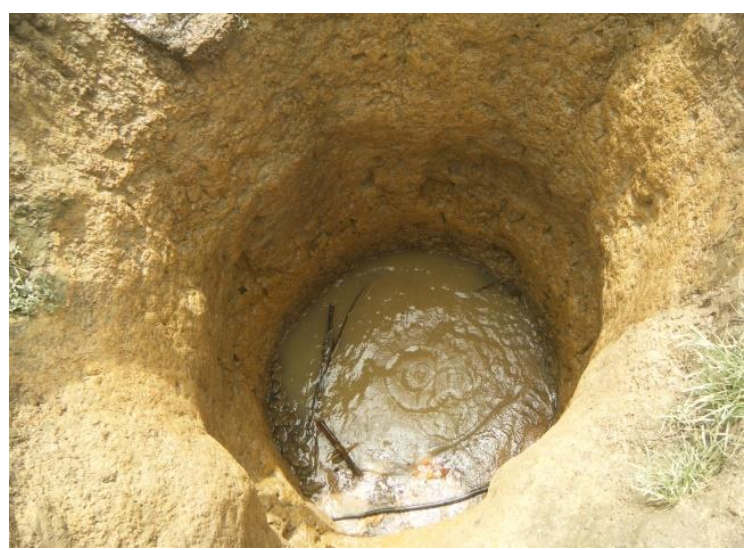

Photo 8: Water hole in Gomparou

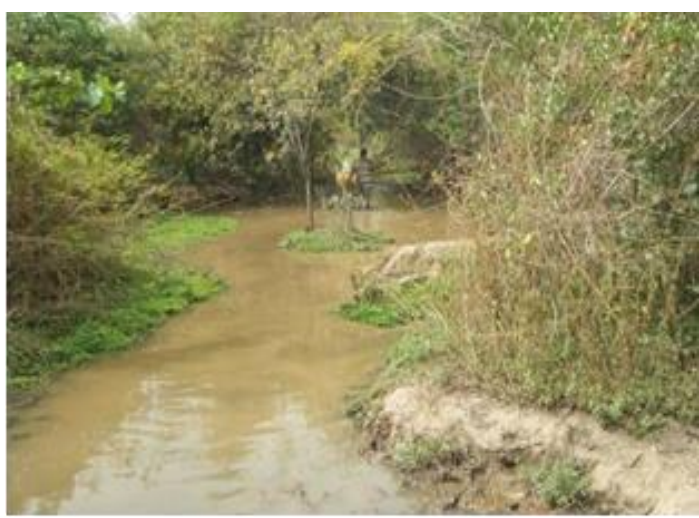

Photo 7: Portion of the Mékrou river in Founougo

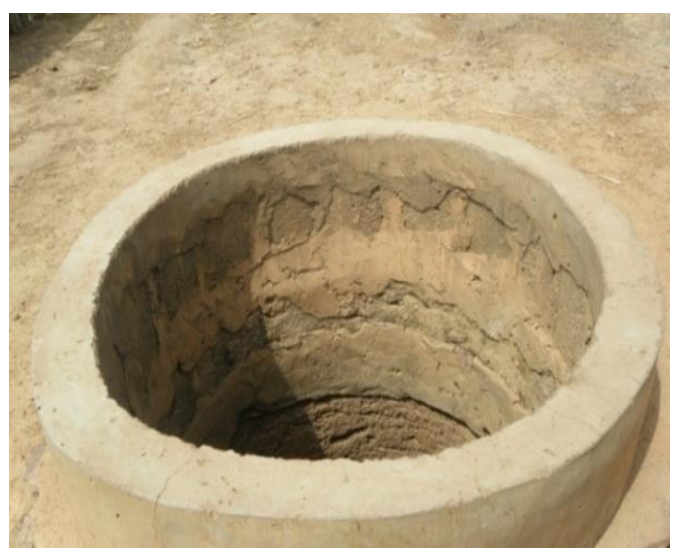

Photo 9: Traditional well in Sompérékou

Plate 1: Some water access structures in Banikoara

Shooting: Yetongnon, 2019

\subsection{Problems related to the household drinking water supply}


In the Municipality of Banikoara as in other areas where the water problem arises, several difficulties are encountered by the populations. These different problems vary from urban to rural areas, and depending on the average level of household income, their geographical location in relation to the water point and the infrastructure that exists. drinking water, measured by the type of supply, the distance and the cost of the purchase, seems to reflect the different methods of access to drinking water and the inherent socio-health risks.

The distance here corresponds to the distance between the water points and the homes. The drudgery of water supply is determined by the constraint on households, especially in areas not provided with hydraulic works or as a result of deficiencies in the availability of water. The chore here consists of fetching water more than 30 minutes or even an hour away from home in 25-30 liter containers using wheelbarrows,

One of the difficulties encountered by the populations is the not insignificant distance they travel back and forth to obtain water from the SONEB, village waterworks, traditional wells or rivers. This long distance traveled by women and children makes them very vulnerable because they have less time to go about other economic activities. It is one of the most important factors for the empowerment of women. The reduction of this distance makes it possible to increase the resilience of women and they will be able to devote themselves more to the care of their children, to their income-generating activities and, in turn, to clearly improve their nutritional status (Tomkins et al. Cited by Alinsato et al .; 2010).

\section{DISCUSSIONS}

Insufficient hydraulic structures are inherent in many cities in Africa, and to this end, Mpakam $\mathrm{H}$ et al. (2006), showed that in the city of Bafoussam very few households benefit from a home connection. In general, the network follows major secondary axes. This implies that neighborhoods with dense unstructured spontaneous housing will be the least served in water. The ration is very low because for a total population of 360,745 inhabitants, in September 2005 there were only 13,511 subscribers. Less than $10 \%$ of the households surveyed are connected to the SNEC network. Households who find themselves unable to pay for a connection have access to water either by paying for consumption well above the normal price through paying standpipes or connected informal resellers, or by obtaining supplies from from alternative structures such as wells and springs, or directly in waterways. One of the major problems of access to drinking water according to Koumassi (2011) is due to the increase in the population and urban sprawl, the water service cannot cover everything. Indeed, demographic growth has been accompanied by that of needs and services in terms of drinking water and sanitation. And Bazié JB (2014) to add that the strong urbanization experienced by the continent in recent decades (4\% urban growth per year), at the same time leads to areas of concentration of populations, especially in the outskirts of large cities. -capital, making complex and costly the responses to be put in place to roll out drinking water services and make them accessible to the greatest. Clearly, the pace of investments in the water and sanitation sector does not is not up to the demographic growth, the strong urban growth of the continent and its needs for water and sanitation services. 
According to the same author, the difficulties of access to water lie in the hydrological and hydrogeological context, the dispersion of the habitat, the small size of certain human communities and the low level of household income. But the efforts made by the government of Benin for more than 15 years in the field of drinking water supply in rural areas have been very important and have made it possible to clearly improve this situation (MMEH, 2003). However, an analysis of the situation shows that demand remains strong both in terms of the number of works to be carried out and for the improvement of the service provided by current equipment. Moreover, from the same source, it appears that the durability of the equipment installed is not yet fully guaranteed everywhere (COMLANVI, M. F, 1995).

\section{CONCLUSION}

Access to water is the basis of human progress. It is as much a factor of development as its result. Not being able to enjoy this most basic human right affects human capital from an economic, health and social perspective. The diagnosis of the problems related to the drinking water supply to households in the municipality of Banikoara allowed us to gain a better understanding of the drinking water supply problems and its socio-sanitary issues. Improving access to drinking water will increase the resilience of populations, especially women, which will improve their productivity. And the increase in the productivity of the populations will improve their contribution to the development of the municipality. In any case, if access to drinking water is a necessary development stage to respond to socio-health issues, each of the actors involved, including the populations themselves, will have to reflect on the problem facing them. becomes a big challenge.

\section{REFERENCES}

ADAM K. S., BOKO M., (1993): Benin. Cotonou: Sodimas and Paris: EDICEF, 96p.

AMOU R. T., (2012): Drinking water and water-borne diseases in the town of Dangbo. Master's thesis, 73p.

Health statistics yearbook 2010 - Banikoara health zone; report, 79p.

Bazié JB (2014). Access to water: Africa between abundance and scarcity. The day after tomorrow N 31-32, NF (3): 28-29.

BOKO G., AMOUSSOU E. and BOKO M., (2009): Assessment of the impacts of human activities on the environment of the commune of Banikoara in northern Benin (West Africa), report, $15 \mathrm{p}$

CHRISTOPH et al. (2009): IMPETUS Atlas of Benin. Third edition in French, 144 p.

Comlanvi, M. F. (1995). Improvement of the quality of well water in the city of Cotonou: case of some neighborhoods. End of studies thesis, University Polytechnic College, Cotonou (Benin). 
Vol. 5, No. 05; 2020

ISSN: $2456-8643$

JOSLING T, (2010). Trade Policy for Food Security: Agricultural Policies in Developed Countries ", International Center for Trade and Sustainable Development, vol. 9, no 5, June 15, 2010

KOUMASSI D. H., (2011): Socio-economic aspects of water resources management in the town of Savalou. DEA thesis, 78p.

KOUMASSI D. H., (2009): Problem of water in the town of Savalou: case of the district of Logozohè. Master's thesis, $87 \mathrm{p}$.

MMEH. (2003). How to obtain a drinking water point? Re-Source de vie news magazine, issue 002 from November-December.

Mpakam $\mathrm{H}$ et al. (2006). Access to drinking water and sanitation in cities of developing countries: the case of Basoussam (Cameroon). VertigO - the electronic journal for environmental sciences (Volume 7 Number 2). http://journals.openedition.org/vertigo/2377 (September 18, 2020).

WHO, (1990). Impact of the International Decade of Drinking Water and Sanitation on diarrheal diseases. Geneva, $17 \mathrm{p}$.

WHO, and UNICEF. (2017). Access to water and sanitation around the world. https://www.who.int/fr/news-room/detail/12-07-2017-2-1-billion-people-lack-safe-drinkingwater-at-home-more-than-twice- as-many-lack-safe-sanitation

National Water Policy (2008), activity report, 51 p.

SOGLO Y. Y., ALINSATO A. and GBINLO E., (2010): Drinking water supply in Benin: problems and prospects. Report, $68 \mathrm{p}$. 